\title{
The outcome of congenital duodenal obstruction in infancy in Erbil
}

\begin{tabular}{ccc}
\hline Karzan K. Hussein* & Nooraddin Ismaeel** & Salar S. Perdawd*** \\
\hline Abstract
\end{tabular}

Background and objective: Duodenal atresia and stenosis is considered a frequent cause of intestinal obstruction in the newborn, good prenatal work up and investigation make early diagnosis and better prognosis. This study aimed to evaluate the prenatal diagnosis, types, post-delivery management, associated anomalies, operative management and outcomes in neonates with congenital duodenal obstruction.

Methods: A prospective study including 21 infants (13 female and eight male) with congenital duodenal obstruction were treated at Rapareen Teaching Hospital in Erbil from December 2011 to December 2015.

Results: The mean age at presentation was 8.1 days (range 4 to 52 days), and the mean weight was 2.63 kilogram. Around $95 \%$ were term and $61.9 \%$ of patients delivered through cesarean section. The commonest presentation was bilious vomiting in $95.2 \%$ of cases. Associated anomalies were present in six cases in particular Down's syndrome in five cases. Plain abdominal x-ray, ultrasound of abdomen and echocardiography done for all cases while upper gastrointestinal contrast study was done only in 5 cases. All managed operatively through laparotomy, and diamond shaped duodenoduodenostomy was the main procedure done in 17 cases, web resection in two cases, Ladd's procedure in one case and duodenojejunostomy in one case. The survival was $95.2 \%$.

Conclusion: Congenital duodenal obstruction is a common condition facing the pediatric surgeon. Associated anomalies is the first factor influencing the outcome. The most common causes of congenital duodenal obstruction were atresia, and annular pancreas and the most important warning sign is the bile stained vomiting. Treatment should be expedient and concurrent with ongoing resuscitation.

Keywords: Congenital duodenal obstruction; Infants; Erbil.

\section{Introduction}

Duodenal atresia and stenosis is considered the frequent cause of intestinal obstruction in the newborn; ${ }^{1}$ the incidence has been variously estimated as 1 in 10 000 - 40000 births. $^{2}$ The obstruction may be either partial or complete, extrinsic (annular pancreas and malrotation) or intrinsic (Atresia and stenosis). ${ }^{3}$ Associated polyhydramnios is recorded in $50 \%$ of the cases, with premature delivery in one third. Growth retardation is common, and almost $50 \%$ of cases are associated with some other anomaly (e.g., cardiac, genitourinary, anorectal and occasionally, esophageal atresia. Up to $40 \%$ have trisomy 21 (Down's syndrome). ${ }^{4}$ The site of obstruction in the majority are postampullary $(90 \%)$, the proximal duodenum and stomach dilate, and the bowel distal to the obstruction is collapsed. Because the obstruction is high, it is decompressed proximally in utero, and perforation proximally is rare. ${ }^{5}$ The classic presentation is bilious emesis within the first hours of life in an otherwise stable neonate; the abdomen is scaphoid. For patients with stenosis, the diagnosis is often delayed until the neonate has started

* Department of Pediatric Surgery, Rapareen Teaching Hospital, Erbil, Iraq.

* Department of General Surgery, College of Medicine, Hawler Medical University, Erbil, Iraq.

* Department of Pediatric Surgery, College of Medicine, Hawler Medical University, Erbil, Iraq. 
on enteral feeds and feeding intolerance develops with emesis and gastric distention. ${ }^{5}$ Radiographs of the abdomen usually document the presence of classic double bubble sign, scattered small amounts of air seen distal to the obstruction are consistent with duodenal stenosis. ${ }^{6}$ Some cases are not recognized until adult life, usually in association with peptic ulceration, reflux esophagitis, or obstruction of the duodenum proximal to the stenosis by a bezoar or foreign body. ${ }^{7}$ The duodenal obstruction is a relative emergency, and the patient should not be rushed to the operating room until hemodynamic status and fluid and electrolyte status are normalized. ${ }^{8}$ The abdomen is entered best through a transverse right upper quadrant incision, a standard side-to-side or, preferably, proximal transverse-to-distal longitudinal (diamond-shaped) anastomosis may be performed using fine interrupted suture. ${ }^{9}$ If the proximal duodenum is excessively floppy and distended, an ant mesenteric tapering duodenoplasty or plication may be useful. ${ }^{10}$ In patients with an annular pancreas, the pancreatic tissue should not be divided to avoid fistula formation, but duodenoduodenostomy should be performed. ${ }^{11}$ The early complication may be associated with the anastomotic leak, injury to the bile duct. ${ }^{12}$ Late complications are reported to occur in $12 \%$ to $15 \%$ of patients such as blind loop syndrome, mega duodenum with abnormal duodenal motility, duodenogastric reflux and esophagitis, abdominal pain, diarrhea, pancreatitis, cholecystitis, and cholelithiasis. ${ }^{9} \quad$ Up to the researcher's knowledge, no studies have been done on this issue in Erbil city. This analytical study aimed to determine the outcome of infants with duodenal obstruction in Erbil. The specific objectives of the study included evaluating the prenatal diagnosis, types, post-delivery management, associated anomalies, operative management and outcomes in neonates with congenital duodenal obstruction admitted to pediatric surgery unit in Rapareen Teaching Hospital in Erbil city.

\section{Methods}

A sample of 21 infants (13 female and eight male) with congenital duodenal obstruction were treated at Rapareen Teaching Hospital for Children-Erbil from December 2011 to December 2015. Details collected in regard of age at operation, sex, gestational age, other medical problems or anomalies, preoperative clinical data, type and results of imaging studies, operative finding, and details of surgical Technique, duration of postoperative gastric decompression, time required for resumption of oral intake, hospital stay which was between 3-12 days, and postoperative complications. The preoperative period ranged from 0-4 days. On admission, full history and examination were done, including the presenting symptoms, associated anomalies, family history of congenital anomalies, and history of maternal polyhydramnios documented by ultrasound examination. Investigations performed included plain abdominal X-ray in all cases, upper G.I. contrast study in 6 cases and abdominal ultrasound examination for all cases. After admission, the patients were kept on nothing by mouth, gastric decompression, fluid and electrolytes replacement and broad spectrum antibiotic coverage. Laparotomy was done in all the cases. The method of data collection was by a questionnaire filled by parents and given an identity number (ID). The data were transported into the statistical package for the social sciences (version 20). Descriptive statistics (numbers and percentage) were calculated for all variables.

\section{Results}

The female to male ratio was $1.6: 1$ and the mean age at the presentation was 8.1 days (range 4 to 52 days). The mean weight was 2.63 kilogram, and the majority of them were term $(95.2 \%)$ as shown 
in Table 1. Three patients (14.3\%) had a prenatal diagnosis by the prenatal US which revealed dilated upper duodenum with double babble sign and 15 of patient's mothers developed polyhydramnios during pregnancy. Associated anomalies were present in six $(28.6 \%)$ cases in particular Down syndrome was found in five $(23.8 \%)$ cases, cardiac problems in three (14.2) cases which were (one large ventricular septal defect and two small patent ductus arteriosus). The commonest presentation was bilious vomiting in $20(95.2 \%)$ cases followed by abdominal distention in 12 $(57.1 \%)$ cases as shown in Table 2. All managed operatively through laparotomy, the obstruction in $12(57.1 \%)$ cases was due to duodenal atresia and Annular pancreas represented second most common finding appeared in five $(23.8 \%)$ cases, duodenal stenosis due to fenestrated web or membrane found in three $(14.3 \%)$ cases and finally one $(4.8 \%)$ case of duodenal obstruction was due to ladds band from malrotation as shown in Table 3. The operative procedure was chosen according to underlying obstructive pathology in them diamond shaped duodenoduodenostomy as described by Kimura was the main procedure done in $17(81 \%)$ cases, web resection with duodenoplasty in two $(9.5 \%)$ cases, Ladd's procedure in one $(4.8 \%)$ case and duodenojejunostomy in one $(4.8 \%)$ case. Mean hospital stay was six days. Twenty $(95.2 \%)$ cases are alive after good post-operative care, one $(4.8 \%)$ case died the day after operation due to delay presentation and suffering from severe dehydration and sepsis with perforated viscus in addition to the association with Down's syndrome and cardiac anomaly.

Table 1: Age and weight at presentation, gestational age.

\begin{tabular}{llcc}
\hline Variables & & No. & $\%$ \\
\hline Age at presentation(days) & $<7$ & 12 & 57.1 \\
& $7-14$ & 5 & 23.8 \\
\multirow{2}{*}{ Weight at presentation(gm) } & $>14$ & 4 & 19.0 \\
& $>2500$ & 7 & 33.3 \\
Gestational age (weeks) & $>3700$ & 14 & 66.7 \\
Total & $>37$ & 1 & 8.4 \\
\hline
\end{tabular}

Table 2: Presenting sign and symptoms.

\begin{tabular}{lcc}
\hline Clinical features & No. of patients & $\%$ \\
\hline Bilious vomiting & 20 & 95.2 \\
Non bilious vomiting & 1 & 4.8 \\
Abdominal distention & 12 & 57.1 \\
Dehydration & 7 & 33.3 \\
Physiological jaundice & 5 & 23.8 \\
\hline
\end{tabular}

Table 3: Causes of obstruction.

\begin{tabular}{lcc}
\hline Causes & No. of patients & $\%$ \\
\hline Duodenal atresia & 12 & 57.1 \\
Annular pancreas & 5 & 23.8 \\
Duodenal stenosis & 3 & 14.3 \\
Ladd's band & 1 & 4.8 \\
Total & 21 & 100 \\
\hline
\end{tabular}




\section{Discussion}

In our study, female (13 cases) were affected more than males (8 cases), with a male to female ratio of $1: 1.6$ which is in contrast to most studies where males affected more than females as in Qing Jiang Chen et al. (2:1), ${ }^{13}$ Li-yi Tsai et al. $(1.1: 1)^{14}$ and Naima Zamir et al. $(3: 1)^{15}$ but near to Baily et al. in which female affected more in a ratio of $1.1: 1 .{ }^{40}$ Twenty $(95.2 \%)$ cases were full-term infants, and one $(4.8 \%)$ case was preterm this was far from the Irving et al. ${ }^{17}$ in which preterm reached $40 \%$ this may reflect our deficient preterm mortality rate and the relatively small study volume. Birth weight ranged from $1600-4500 \mathrm{gm}$ (mean 2637gm); this is comparable with Al-Salem et $\mathrm{al}^{18}$ in which the mean weight at presentation was $2050 \mathrm{gm}$. Polyhydramnios was found in 15 $(71.4 \%)$ cases during antenatal ultrasound checkup which was consistent with Pablo Aguayo et al. ${ }^{5}$ in which ranged between $32-81 \%$. In general associated anomalies found in $6(28.5 \%)$ cases while down syndrome alone represented in five $(23.8 \%)$ cases, these results were low in comparison to those written in Pablo Aguayo et al. $^{5}$ in which associated anomalies present in 50\% and down syndrome in $30 \%$, the explanation may be logical if linked to our clinical diagnosis of Down syndrome rather than chromosomal study and most cases of subtle cardiac defect have been missed during echocardiography examination due to emergency situation and lack of availability in hospital most of the time. Bilious vomiting was the main presentation postnatally seen in $20(95.2 \%)$ cases while only one $(4.8 \%)$ patient developed non bilious vomiting due to pre-ampullary duodenal obstruction, this is comparable to study done by Qing Jiang Chen et al. (bilious vomiting $83.8 \%$ ). $^{13}$ In our study, duodenal atresia was the most common intraoperative finding comprising 12 $(57.1 \%)$ cases and annular pancreas in five $(23.8 \%)$ cases and duodenal stenosis in three $(14.3 \%)$ cases and obstruction due to ladds band in one (4.8\%) case, these findings are comparable with most literature ${ }^{5,19}$ except for annular pancreas, which appeared higher in our study and is supposed to be due to underlying duodenal atresia in association with annular pancreas. Sometimes this can be explained that some cases of annular pancreas are not a true annular pancreas. Occasionally the atresia is associated with pancreatic tissue that may surround the duodenum. Surgery was done for all cases. Diamond shaped duodenoduodenostomy popularized by kimura was done for cases of duodenal atresia, annular pancreas, web resection with duodenoplasty in two cases of duodenal stenosis and ladds procedure in one case due to obstructive ladds band of malrotation. These were completely consistent and comparable with Qing Jiang Chen et al., ${ }^{13}$ Naima Zamir et al. $^{15}$ and Kedah SN et al. ${ }^{20}$ Regarding the Outcome $20(95.2 \%)$ cases survived and this comparable with most literature..$^{5,19,21}$ The only case who died the day after operation was due to the delayed referral from rural area causing severe dehydration and sepsis with his association with down syndrome and cardiac anomaly.

\section{Conclusion}

Congenital Duodenal obstruction is a common condition facing the pediatric surgeon in his life. The absence of other anomalies is considered a useful prognostic factor regarding the outcome. Early diagnosis can permit time for screening, possible early correction and avoiding the development of complications. The most common causes of congenital duodenal obstruction were atresia, and annular pancreas and the most important warning sign is the bile stained vomiting. Treatment should be expedient and concurrent with ongoing resuscitation and frequently complicated by prematurity and associated severe anomalies. 


\section{Competing interests}

The authors declare that they have no competing interests.

\section{References}

1. Nixon $\mathrm{HH}$, Tawes R. Etiology and treatment of small intestinal atresia. Surgery 1971: 69:41-51.

2. Schnauffer L. Duodenal atresia, stenosis and annular pancreas. In: Welch KJ, Randolph JG, Ravitch MM (eds). Pediatric surgery, $4^{\text {th }}$ ed. Chicago: Book Medical; 1991. P. 829-37.

3. Calkins CM, Karrer F, Deodhar J. Duodenal Atresia. E Medicine Word Medical Library, 2003.4.

4. Alastair JW, Heinz Rod M, Cywes S. Intestinal Atresia And Stenosis: Pediatric Surgery, $4^{\text {th }}$ ed. by Elsevier Inc., 2005; 416-34.

5. Aguayo P, Ostlie DJ. Duodenal and intestinal atresia and stenosis, London; New York: Saunders/Elsevier; 2014. P. 415.

6. Enochsson L, Runold M, Fenyo G . Contrast radiography in small intestinal obstruction, a valuable diagnostic tool. Eur J Surg 2001; 167 (2):120-4.

7. Pathak D, Sarin YK. Congenital duodenal obstruction due to a preduodenal portal vein. Indian J Pediatr 2006; 73(5):423-5.

8. Upadhyay V, Sakalkale R, Parashar K, Mitra SK, Buick RG, Gornall P, et al . Duodenal atresia: a comparison of three modes of treatment. Eur $\mathrm{J}$ Pediatr Surg 1996; 6:75-7.

9. Bowen J, Dickson A, Bruce J. Reconstruction for duodenal atresia. J Pediatr Surg 1996; 11:474.

10. Gavopoulos S, Lima CH, Avtzoglou P. Operative and postoperative management of congenital duodenal obstruction. Pediatr Surglnt 1993; 8:122-4.

11. Weaver E . Operative Management of duodenal atresia. Pediatr Surg Int 1995;10:332.

12. Kimura K, Mukahara N, Nishijima E. Diamond shaped anastamosis for duodenal atresia. Pediatr Surg 1996; 25:977.

13. Qing-Jiang Chen, Zhi-Gang Gao. Congenital duodenal obstruction in neonates: a decade's experience from one center, World $\mathrm{J}$ Pediatr 2014; 10(3):238-44.

14. Tsai LY, Hsieh WS, Chen CY, Chou HC, Tsao PN, Hsu WM. Distinct clinical characteristics of patients with congenital duodenal obstruction in a medical center in Taiwan. Pediatr Neonatol 2010; 51(6):343-6.

15. Zamir N, Akhtar J. Neonatal duodenal obstruction: Clinical presentation and outcome. Pakistan J Surgery 2013; 18(4):182-5.

16. Bailey PV, Tracy TF Jr, Connors RH, Mooney DP, Lewis JE, Weber TR. Congenital duodenal obstruction: a 32-years review. J Pediatric Surg 1993; 28(1):92-5.
17. Irving IM, Rickham PP. Duodenal atresia and stenosis; annular pancreas. In: Rickham PP, Lister J, Irving IM (eds). Neonatal surgery, $2^{\text {nd }}$ ed. Boston: Butterworth; 1990. P. 355-70.

18. Al-Salem $\mathrm{AH}$. Congenital intrinsic duodenal obstruction: a review of 35 cases. Saudi Med 2007; 27(4):289-92.

19. Sweed Y. Duodenal obstruction. In: Puri P (ed) Newborn surgery. Arnold. London: CRC Press 2003. P. 423-33.

20. Kaddah SN, Bahaa-Aldin HK, Fayad Aly H, Hassan HS. Congenital duodenal obstruction. Ann Pediatr Surg 2006; 2(2):130-5.

21. Apple BH, Lee SL, Puapong DP. Duodenal atresia and stenosis - annular pancreas. In: Grosfeld, O'Neill, Fonkalsrud, and Coran. Pediatric Surgery. Philadelphia, PA: Mosby Elsevier; 2006. P.1260-8. 